\title{
A randomized, double-blind, placebo-controlled trial of cyproheptadine for appetite stimulation in cystic fibrosis

\author{
Matias Epifanio, ${ }^{1}$ Paulo C. Marostica, ${ }^{1}$ Rita Mattiello, ${ }^{2}$ Larissa Feix, ${ }^{3}$ \\ Regina Nejedlo, ${ }^{4}$ Gilberto B. Fischer, ${ }^{5}$ Renato T. Stein ${ }^{6}$
}

\begin{abstract}
Objective: To determine whether the administration of cyproheptadine was able to induce weight gain in patients with cystic fibrosis.

Methods: We performed a double-blind, placebo-controlled trial in two centers in Brazil. Twenty-five patients with cystic fibrosis between 5 and 18 years completed the study. Patients were randomized into two groups, to receive either cyproheptadine $4 \mathrm{mg}$ three times per day for 12 weeks or placebo. All data were collected at the beginning and at the end of the study period and included weight, height and spirometry.

Results: Average weight gain was $0.67 \mathrm{~kg}$ in the placebo group and $1.61 \mathrm{~kg}$ in the cyproheptadine group $(p=0.036)$. Body mass index (BMI) decreased $0.07 \mathrm{~kg} / \mathrm{m}^{2}$ in the placebo group and increased $0.46 \mathrm{~kg} / \mathrm{m}^{2}$ in the intervention group $(p=0,027)$. The change in BMI for age ( $z$ score) was -0.19 in the placebo group and +0.20 in the cyproheptadine group $(p=0.003)$. BMI $z$ score decreased 0.19 in the placebo group and increased 0.2 in the cyproheptadine group $(p=0.003)$. Changes in pulmonary function were not statistically different.

Conclusion: Use of cyproheptadine in cystic fibrosis patients was well tolerated, showing a significant weight gain and a significant increase in BMI after 12 weeks. A clinically relevant effect size for weight/age (z score) and body mass index for age (z score) was found. Such findings suggest that the prescription of cyproheptadine can be an alternative approach for patients who need nutritional support for a short period of time.
\end{abstract}

J Pediatr (Rio J). 2012;88(2):155-60: Cyproheptadine, weight gain, cystic fibrosis, appetite stimulant.

\section{Introduction}

Patients with cystic fibrosis (CF) may have poor nutritional status due to poor digestion and malabsorption from pancreatic insufficiency, associated with frequent respiratory infections. ${ }^{1}$ Weight loss and malnutrition contribute directly to the decline in lung function, leading to worse quality of life and increased morbidity and mortality. ${ }^{2,3}$

The primary goal of nutritional management in CF patients is to achieve an adequate nutritional status and normal growth and development. ${ }^{3}$ Strategies to help increase the weight of CF patients include supplementary feeding by mouth or by enteral feeding (gastrostomy and nasogastric tube). However, these methods are invasive, expensive and interfere with patient's self-esteem and body image. ${ }^{4,5}$ Appetite stimulants may be used to regain or increase appetite, and improve the nutritional status of these patients.

1. Doutor. Médico, professor, Hospital São Lucas, Pontifícia Universidade Católica do Rio Grande do Sul (PUCRS), Porto Alegre, RS, Brazil.

2. Doutora. Fisioterapeuta, Instituto de Pesquisas Biomédicas, PUCRS, Porto Alegre, RS, Brazil.

3. Mestre. Nutricionista, Porto Alegre, RS, Brazil.

4. Farmacêutica. Quinta Essência Indústria Cosmética, Porto Alegre, RS, Brazil.

5. Professor titular, Pediatria, Universidade Federal de Ciências da Saúde, Porto Alegre, RS, Brazil.

6. Doutor. Médico, professor, Instituto de Pesquisas Biomédicas (IPB), Hospital São Lucas, PUCRS, Porto Alegre, RS, Brazil.

No conflicts of interest declared concerning the publication of this article.

Suggested citation: Epifanio M, Marostica P, Mattiello R, Feix L, Nejedlo R, Fischer G, et al. A randomized, double-blind, placebo-controlled trial of cyproheptadine for appetite stimulation in cystic fibrosis. J Pediatr (Rio J). 2012;88(2):155-60.

Manuscript submitted Aug 4 2011, accepted for publication Jan 42012.

http://dx.doi.org/10.2223/JPED.2174 
Cyproheptadine $(\mathrm{CH})$ is a first generation antihistamine with antiserotonergic properties and a secondary effect of stimulating appetite. There are studies using $\mathrm{CH}$ as appetite stimulant in patients with malnutrition, anorexia nervosa, renal failure, cancer and AIDS, ${ }^{6-10}$ but studies with $\mathrm{CH}$ in patients with CF are still scarce. 5,11

The present study aimed to determine whether administration of $\mathrm{CH}$ induces weight gain in children and adolescents with CF.

\section{Methods}

A randomized, double-blind placebo-controlled trial was conducted from May 2010 to February 2011. It included children and adolescents previously diagnosed with CF based on international recommendations, ${ }^{12}$ with ages between 5 and 18 years and weight for age ratio < 85\%. Subjects were all followed up periodically at the CF pediatric pulmonology outpatient clinics of Hospital São Lucas (HSL) at Pontifícia Universidade Católica do Rio Grande do Sul (PUCRS) or Hospital da Criança Santo Antônio, in Porto Alegre, Southern Brazil. Exclusion criteria were subjects with a history of antihistamines intolerance, or receiving sedatives, narcotics, steroids, or appetite stimulants within 30 days prior to enrollment. Children and adolescents having comorbidities that might interfere with the outcomes of the study or unable to perform reproducible spirometric maneuvers were also excluded.

The study was registered in the Australia and New Zealand Clinical Trials Registry under number ACTRN12611000127909 and it is in accordance with recommendations from the Consolidated Standards of Reporting Trials (CONSORT). ${ }^{13}$

Patients were randomized into two groups divided by blocks of ten using the software PEPI- Statistical \& Stat Calc Suite. ${ }^{14}$ Bottles containing $\mathrm{CH}$ or placebo were packed in opaque envelopes. The envelopes were delivered to the researcher according to each patient's scheduled appointments at the outpatient clinics. Each patient received a kit containing two vials and metered syringes. The initial vial contained $60 \mathrm{~mL}$ of either $\mathrm{CH}$ or placebo to be used during the first week, and one vial containing 240 $\mathrm{mL}$ of the same treatment for the rest of the intervention period. Appearance, smell and taste of the syrups were identical in both groups. Concentration varied in the two bottles delivered to patients in the $\mathrm{CH}$ group; the first vial contained $2 \mathrm{mg}$ in $1 \mathrm{~mL}$ of the syrup to evaluate possible undesirable side effects, such as sedation and somnolence, that might be present up to three or four days after starting the treatment. The second vial contained placebo or $4 \mathrm{mg} /$ $\mathrm{mL}$ of $\mathrm{CH}$. Thus, both groups were instructed to always take $1 \mathrm{~mL}$ of syrup for the 12 weeks of treatment.

On the CF outpatient clinic visits (before taking the medication and after 12 weeks) clinical history, nutritional and anthropometric assessment, and pulmonary function testing were performed in each patient. Nutritional anamnesis was performed, inquiring items relative to use of enzymes, vitamin supplements, food supplements, gastrostomy tube feeding, and associated diseases.

Anthropometric measurements were performed in accordance with the recommendations of the World Health Organization (WHO). ${ }^{15}$ Weight and height measurements were taken using a digital scale (TOLEDO Filizola ${ }^{\circledR}$ Personal Digital Model) with maximum capacity of $180 \mathrm{~kg}$ and a minimum of $2 \mathrm{~kg}$, with a $100 \mathrm{~g}$ resolution, and a stadiometer for heights up to $192 \mathrm{~cm}$. Weight and height were always measured in duplicate by one of the researchers (LF). Patients were asked to wear light clothes. The weight and height measurements were performed according to international standards. ${ }^{16,17}$ Classification of nutritional status of participants was done in accordance with weightfor-age $z$ score (W/A) reference distribution of the Centers for Disease Control and Prevention (CDC, 2000), calculated using Epi-Info ${ }^{\mathrm{TM}}$ software.

The values obtained for body mass index (BMI) were compared with the reference proposed by WHO.18 The calculation was performed using software available in AnthroPlus at http://www.who.int/growthref/tools/en/.

Lung function testing was performed by experienced physicians using the Koko spirometer (Ferraris, USA). International recommendations were followed for acceptability and reproducibility criteria. ${ }^{19}$ Pulmonary function was expressed as a percentage of the predicted value using Pereira's reference equations. ${ }^{20,21}$

Analysis and data processing were performed using the Statistical Package for the Social Sciences (SPSS) version 14.0 (SPSS Inc., Chicago, USA). Skewness was assessed using the Kolmogorov-Smirnov test; continuous variables were expressed as mean and standard deviation, while categorical variables were expressed as absolute and relative frequency. The study compared outcomes between the two groups using Student's $t$ test for continuous variables and chi-square test for categorical variables.

Primary outcome was weight/age (z score) and secondary outcomes were weight, weight/age (z score) BMI, and arm muscle circumference (AMC).

Sample size estimate was based on Hominick et al. Twelve patients per group (power $=80 \%$; alpha error $=5.0 \%$ ) were needed to obtain a mean difference of $2.3 \mathrm{~kg}$ in weight gain, with a standard deviation up to $1.9 \mathrm{~kg} .^{5}$

Analysis was performed as intention to treat. Effect size (ES) was calculated using the variation obtained before and after the intervention; for its calculation, the Effect Size Calculator tool from the Curriculum, Evaluation and Management Centre (Durham University, England) was used. ${ }^{22} \mathrm{ES}$ is a measure of association which estimates the standardized mean difference between two groups. 
The study was approved by the Research Ethics Committee of both institutions; parents signed an informed consent, and children verbally agreed to participate in the study.

\section{Results}

Twenty-five patients completed the study, 14 in the placebo group and 11 in the $\mathrm{CH}$ group, from a total of 25 eligible patients that were invited to participate (Figure 1). Mean age was 9 and 11 years in the placebo and $\mathrm{CH}$ group, respectively. Baseline characteristics between placebo and $\mathrm{CH}$ groups are in Table 1 ; there were no significant differences for sex, age, weight, weight for age (z score values), height, BMI, AMC, BMI for age ratio (z score values), forced expiratory volume in one second $\left(\mathrm{FEV}_{1}\right)$ (percent of predicted), and food intake according to the food frequency questionnaire.

Table 2 shows the results of the placebo and $\mathrm{CH}$ in both groups. Average weight gain was $0.67 \mathrm{~kg}$ in the placebo group and $1.61 \mathrm{~kg}$ in the $\mathrm{CH}$ group $(\mathrm{p}=0.036)$. There was mean change in weight/age (z score) of -0.05 in the placebo group and +0.13 in the $\mathrm{CH}$ group $(\mathrm{p}=0.057)$; BMI decreased $0.07 \mathrm{~kg} / \mathrm{m}^{2}$ in the placebo group and increased
$0.46 \mathrm{~kg} / \mathrm{m}^{2}$ in the intervention group $(p=0,027)$. Change in BMI for age ( $z$ score) was -0.19 in the placebo group and +0.20 in the $\mathrm{CH}$ group $(p=0.003$ ) (Figure 2$)$. BMI $z$ score decreased 0.19 in the placebo group and increased 0.2 in the $\mathrm{CH}$ group $(\mathrm{p}=0.003)$.

No significant differences between groups were found regarding use of dietary supplementation ( $p=0.234)$; eight patients used dietary supplements in the placebo group, while nine patients used some type of supplementation in the $\mathrm{CH}$ group. All subjects used enzymes, and none of them were on gastrostomy tube feeding. In this study, no difference was observed between placebo and intervention groups in terms of variations between the beginning and the end of the study period in energy intake (placebo $=-71.71 \pm 1123.36 \mathrm{kcal}$; $\mathrm{CH}=300.41 \pm 1374.30 \mathrm{kcal} ; \mathrm{p}=0.546) ; \mathrm{FEV}_{1}$ (placebo = $-1.81 \pm 15.30 \%$ of predicted; $\mathrm{CH}=-3.65 \pm 16.22 \%$ of predicted; $\mathrm{p}=0.800$ ), and AMC (placebo $=0.39 \pm 0.73 \mathrm{~cm}$; $\mathrm{CH}=0.57 \pm 0.86 \mathrm{~cm} ; \mathrm{p}=0.460)$.

As to side effects, only two patients in the cohort reported fatigue and sleepiness in the early treatment. One patient showed intolerance and other allergies, leading to discontinuation of $\mathrm{CH}$ in both cases. Two patients did not adhere to the treatment, one in the $\mathrm{CH}$ group and one in the placebo group.

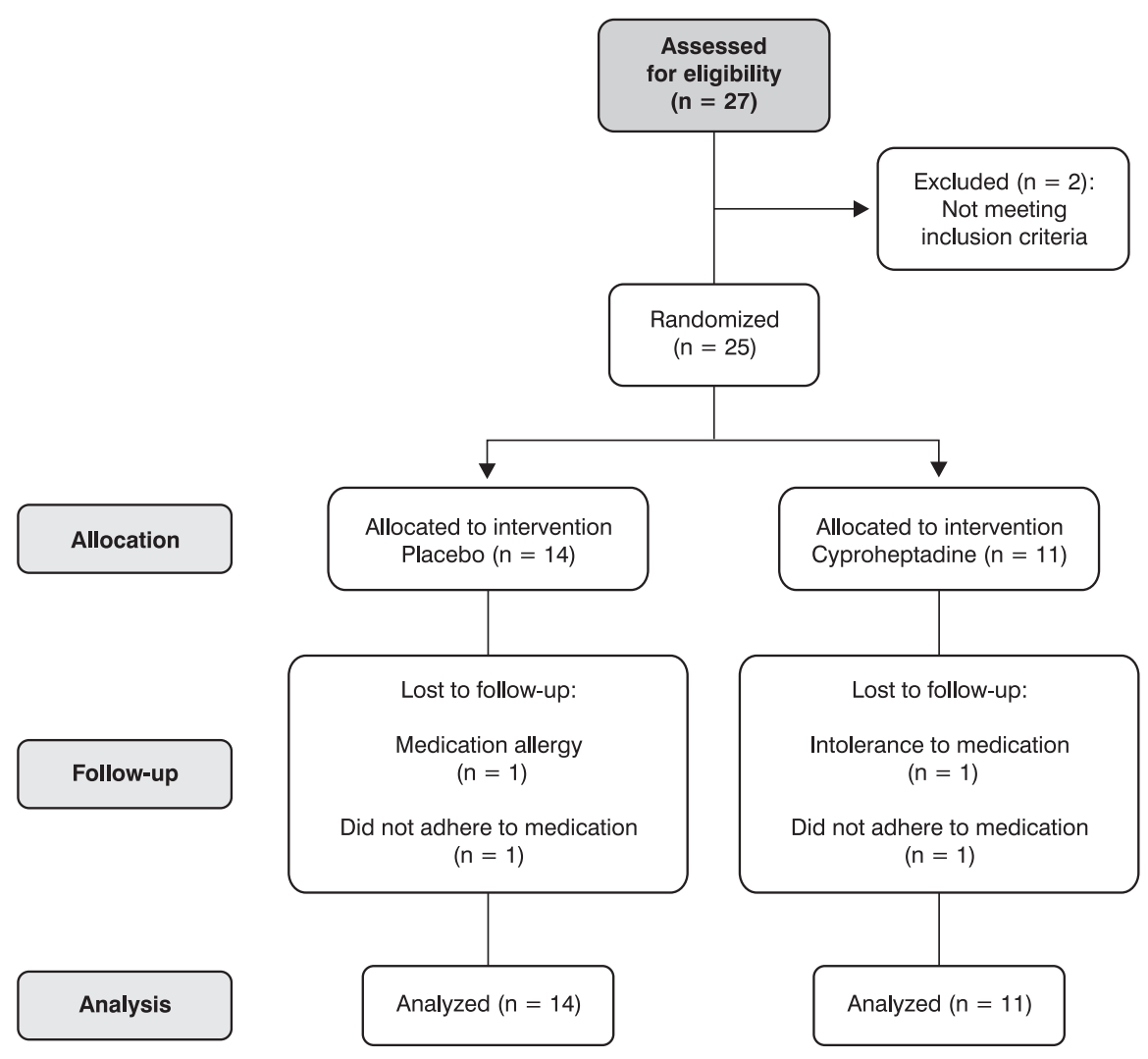

Figure 1 - Flow diagram of the progress through the randomized trial phases of placebo and intervention groups 
Conventional interpretation of ES values is: $0.2=$ small ES; $0.5=$ medium ES; $0.8=$ big ES. ${ }^{22}$ All variables showed a large ES (Table 2).

\section{Discussion}

The features of $\mathrm{CH}$ as an appetite stimulant have been well reported in the medical literature, but clinical trials in
CF are still limited. In the present study, administration of $\mathrm{CH}$ caused significantly greater weight gain, increased BMI and BMI/age $z$ score when compared to placebo. In addition, there was a relevant weight increase as demonstrated by the ES in CF patients after 12 weeks of $\mathrm{CH}$ use.

Homnick et al. conducted a double-blind, placebocontrolled trial with $\mathrm{CH}$ during 12 weeks in $\mathrm{CF}$ patients and their findings were similar to ours. They were able to show a

Table 1 - Baseline characteristics of patients with cystic fibrosis

\begin{tabular}{|c|c|c|c|}
\hline \multirow[b]{2}{*}{ Characteristics } & \multicolumn{2}{|c|}{ Groups } & \multirow[b]{2}{*}{$\mathbf{p}$} \\
\hline & Placebo & $\mathbf{C H}$ & \\
\hline & $\mathrm{n}=14$ & $\mathrm{n}=11$ & \\
\hline Sex (male \%) & $7(50 \%)$ & $7(64 \%)$ & 0.686 \\
\hline Age (years) & $9 \pm 3$ & $11 \pm 3$ & 0.085 \\
\hline Weight (kg) & $31.16 \pm 12.14$ & $36.94 \pm 11.82$ & 0.244 \\
\hline Weight/age (z score) & $-0.39 \pm 0.79$ & $-0.53 \pm 0.87$ & 0.762 \\
\hline Height (cm) & $133.82 \pm 19.35$ & $142.81 \pm 19.19$ & 0.259 \\
\hline BMI $\left(\mathrm{kg} / \mathrm{m}^{2}\right)$ & $16.78 \pm 1.69$ & $17.67 \pm 1.80$ & 0.216 \\
\hline AMC $(\mathrm{cm})$ & $18.91 \pm 2.54$ & $20.14 \pm 2.62$ & 0.248 \\
\hline BMI/age (z score) & $-0.02 \pm 0.72$ & $-0.18 \pm 0.86$ & 0.636 \\
\hline $\mathrm{FEV}_{1}$ (\% predicted) & $97.87 \pm 21.43$ & $95.22 \pm 31.10$ & 0.815 \\
\hline FFQ (Kcal) & $3943.27 \pm 1450.95$ & $2929.47 \pm 972.26$ & 0.080 \\
\hline
\end{tabular}

$\mathrm{AMC}=$ arm muscle circumference; $\mathrm{BMI}=$ body mass index $\mathrm{CH}=$ cyproheptadine; $\mathrm{FEV}_{1}=$ forced expiratory volume in one second;

$\mathrm{FFQ}=$ food frequency questionnaire.

Table 2 - Variation of the groups before and after the use of cyproheptadine

\begin{tabular}{|c|c|c|c|c|}
\hline \multirow[b]{2}{*}{ Characteristics } & \multicolumn{2}{|c|}{ Groups } & \multirow[b]{2}{*}{$\mathbf{p}$} & \multirow[b]{2}{*}{ ES } \\
\hline & Placebo & $\mathbf{C H}$ & & \\
\hline & $\mathrm{n}=14$ & $\mathrm{n}=11$ & & \\
\hline Weight (kg) & $0.67 \pm 0.83$ & $1.61 \pm 1.28$ & 0.036 & 0.896 \\
\hline Weight/age (z score) & $-0.05 \pm 0.16$ & $0.13 \pm 0.24$ & 0.057 & 0.906 \\
\hline $\operatorname{BMI}\left(\mathrm{kg} / \mathrm{m}^{2}\right)$ & $-0.07 \pm 0.47$ & $0.46 \pm 0.65$ & 0.027 & 0.954 \\
\hline BMI/age (z score) & $-0.19 \pm 0.30$ & $0.20 \pm 0.29$ & 0.003 & 1.319 \\
\hline
\end{tabular}

$\mathrm{BMI}=$ body mass index $\mathrm{CH}$ = cyproheptadine; $\mathrm{ES}=$ effect size. 


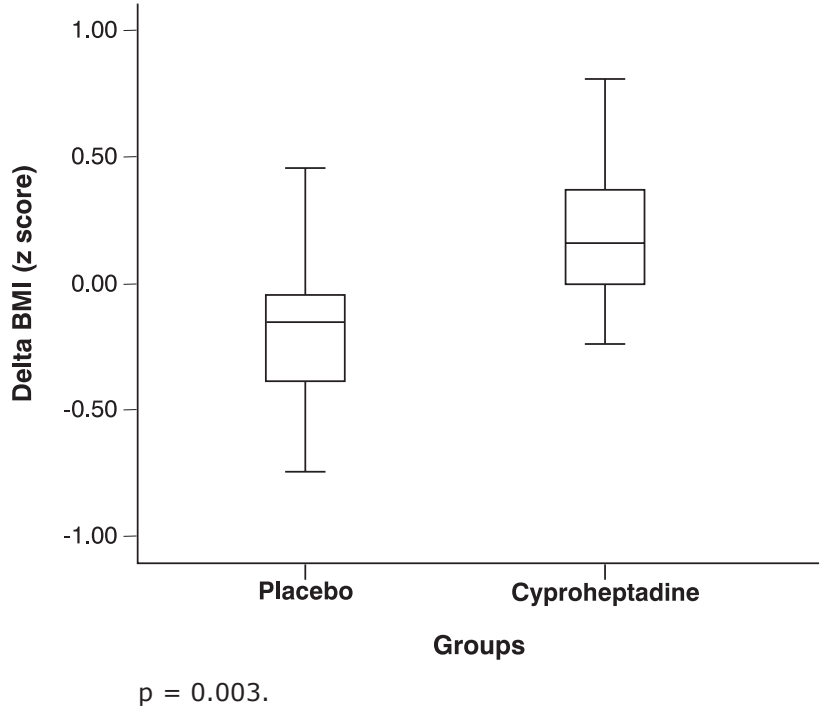

Figure 2 - Variation of body mass index for age (z score) before and after the use of cyproheptadine

significant weight gain and BMI increase in spite of the small number of subjects enrolled. ${ }^{5}$ In a subsequent period in the same study, a crossover design was undertaken. Sixteen eligible CF patients were assigned to receive either placebo or $\mathrm{CH}$ during 12 months according to prior randomization. Results were more significant in the placebo/CH group in terms of weight gain, BMI and body fat increase when compared to patients in the $\mathrm{CH} /$ placebo arm, who showed an increase in nutritional $z$ scores from the beginning to the end of the intervention period. ${ }^{11}$

Our study is in accordance with previous reports and suggests that $\mathrm{CH}$ can be a noninvasive alternative in $\mathrm{CF}$ patients who need weight gain to improve nutritional status. $\mathrm{CH}$ could particularly benefit patients prior to gastrostomy tube insertion or those presenting clinical or functional decline.

A $0.94 \mathrm{~kg}$ weight gain difference was found in the $\mathrm{CH}$ patients as compared with placebo subjects after a 12 -week treatment period. Similar findings were reported in other studies. Rerksuppaphol et al. used $\mathrm{CH}$ in undernourished patients and found significantly higher weight gain when compared to placebo during an 8 -week period. The greatest benefit was detected in the first 4 weeks $(0.9 \mathrm{~kg}){ }^{7}$ Mahachoklertwattana et al., ${ }^{23}$ conducting a 4-week randomized trial, reported a $0.66 \mathrm{~kg}$ weight gain in $\mathrm{CH}$ treated undernourished patients during a 4-week period.

$\mathrm{FEV}_{1}$ was not significantly changed during the trial, possibly due to the short length of the intervention. The correlation between nutritional status and pulmonary function tests in CF is widely known, although interventional studies that proved such relationship were usually longer than ours. ${ }^{24-27}$ Hart et al. also found a correlation between diaphragm strength and nutritional status. ${ }^{28}$ Studies suggest that malnutrition causes lean mass loss, decreasing diaphragm contraction strength and respiratory muscle strength and endurance. On the other hand, increase in respiratory work generates greater energy expenditure, hastening pulmonary function decline. 27,29

No major side effects occurred in the patients receiving $\mathrm{CH}$. Transient drowsiness was reported in $19 \%$ of the patients in the $\mathrm{CH}$ arm. Such findings are in agreement with most studies using $\mathrm{CH} .5,11,23$

A limitation of our study was the small sample size, but in spite of the small number of patients, we were able to demonstrate a statistically significant and clinically relevant weight gain of $1.61 \mathrm{~kg}$ in patients of the $\mathrm{CH}$ arm $(p=0.036)$.

Complete food intake data at baseline and at 4 and 12 weeks were obtained for seven subjects in the $\mathrm{CH}$ group and for eight placebo subjects. Mean caloric intake did not differ significantly between groups at these time points or within groups from the beginning to the end of the study; these results could reflect that the alimentary consumption survey used might not be sensitive enough due to recall bias. More interventional studies comparing the performance of different alimentary consumption surveys are needed, particularly with CF patients. Clinical and psychosocial characteristics of patients with CF may also interfere with the real calculation of energy consumption. ${ }^{30}$

In conclusion, use of $\mathrm{CH}$ in $\mathrm{CF}$ patients was well tolerated, showing a significant weight gain and a significant increase in BMI after 12 weeks. A clinically relevant ES for weight/age (z score) and BMI for age (z score) was found. Such findings suggest that the prescription of $\mathrm{CH}$ can be an alternative approach for patients who need nutritional support for a short period of time.

\section{References}

1. Borowitz D, Baker RD, Stallings V. Consensus report on nutrition for pediatric patients with cystic fibrosis. J Pediatr Gastroenterol Nutr. 2002;35:246-59.

2. Sinaasappel M, Stern M, Littlewood J, Wolfe S, Steinkamp G, Heijerman HG, et al. Nutrition in patients with cystic fibrosis: a European Consensus. J Cyst Fibros. 2002;1:51-75.

3. Cystic Fibrosis Foundation, Borowitz D, Robinson KA, Rosenfeld M, Davis SD, Sabadosa KA, et al. Cystic Fibrosis Foundation evidence-based guidelines for management of infants with cystic fibrosis. J Pediatr. 2009;155:S73-93.

4. Efrati O, Mei-Zahav M, Rivlin J, Kerem E, Blau H, Barak A, et al. Long term nutritional rehabilitation by gastrostomy in Israeli patients with cystic fibrosis: clinical outcome in advanced pulmonary disease. J Pediatr Gastroenterol Nutr. 2006;42:222-8.

5. Homnick DN, Homnick BD, Reeves AJ, Marks JH, Pimentel RS, Bonnema SK. Cyproheptadine is an effective appetite stimulant in cystic fibrosis. Pediatr Pulmonol. 2004;38:129-34. 
6. Mao X, Liang SB, Hurren R, Gronda M, Chow S, Xu GW, et al. Cyproheptadine displays preclinical activity in myeloma and leukemia. Blood. 2008;112:760-9.

7. Rerksuppaphol S, Rerksuppaphol L. Effect of cyproheptadine on weight gain in malnourished children: a randomized, controlled trial. Asian Biomed. 2010;4:977-82.

8. Balog DL, Epstein ME, Amodio-Groton MI. HIV wasting syndrome: treatment update. Ann Pharmacother. 1998;32:446-58.

9. Aguilera A, Selgas R, Diéz JJ, Bajo MA, Codoceo R, Alvarez V. Anorexia in end-stage renal disease: pathophysiology and treatment. Expert Opin Pharmacother. 2001;2:1825-38.

10. Powers PS, Santana C. Available pharmacological treatments for anorexia nervosa. Expert Opin Pharmacother. 2004;5:2287-92.

11. Homnick DN, Marks JH, Hare KL, Bonnema SK. Long-term trial of cyproheptadine as an appetite stimulant incystic fibrosis. Pediatr Pulmonol. 2005;40:251-6.

12. Rosenstein BJ, Cutting GR. The diagnosis of cystic fibrosis: a consensus statement. Cystic Fibrosis Foundation Consensus Panel. J Pediatr. 1998;132:589-95.

13. Schulz KF, Altman DG, Moher D; CONSORT Group. CONSORT 2010 statement: updated guidelines for reporting parallel group randomised trials. BMJ. 2010;340:c332.

14. Abramson JH. WINPEPI updated: computer programs for epidemiologists, and their teaching potential. Epidemiol Perspect Innov. 2011;8:1.

15. World Health Organization. Training Course on Child Growth Assessment. Geneva: WHO; 2008.

16. Jelliffe DB. Evaluación del estado de nutrición de la comunidad. Geneva: WHO; 1968.

17. Frisancho A. Anthropometric standards for the assessment of growth and nutritional status. Michigan: The University of Michigan; 1990.

18. de Onis M, Garza C, Onyango AW, Borghi E. Comparison of the WHO child growth standards and the CDC2000 growth charts. J Nutr. 2007;137:144-8.

19. Miller MR, Hankinson J, Brusasco V, Burgos F, Casaburi R, Coates $A$, et al. Standardisation of spirometry. Eur Respir J. $2005 ; 26: 319-38$

20. Eigen H, Bieler H, Grant D, Christoph K, Terrill D, Heilman DK, et al. Spirometric pulmonary function in healthy preschool children. Am J Respir Crit Care Med. 2001;163:619-23.

21. Sociedade Brasileira de Pneumologia e Tisiologia. I Consenso Brasileiro sobre Espirometria. J Pneumol. 1996;22:105-64.
22. Middel B, Stewart R, Bouma J, van Sonderen E, van den Heuvel WJ. How to validate clinically important change in health-related functional status. Is the magnitude of the effect size consistently related to magnitude of change as indicated by a global question rating? J Eval Clin Pract. 2001;7:399-410.

23. Mahachoklertwattana $P$, Wanasuwankul $S$, Poomthavorn $P$ Choubtum L, Sriphrapradang A. Short-term cyproheptadine therapy in underweight children: effects on growth and serum insulin-like growth factor-I. J Pediatr Endocrinol Metab. 2009;22:425-32.

24. Chaves CR, Britto JA, Oliveira CQ, Gomes MM, Cunha AL. Association between nutritional status measurements and pulmonary function in children and adolescents with cystic fibrosis. J Bras Pneumol. 2009;35:409-14

25. Pedreira CC, Robert RG, Dalton V, Oliver MR, Carlin JB, Robinson P, et al. Association of body composition and lung function in children with cystic fibrosis. Pediatr Pulmonol. 2005;39:276-80.

26. Stark LJ, Opipari-Arrigan L, Quittner AL, Bean J, Powers SW. The effects of an intensive behavior and nutrition intervention compared to standard of care on weight outcomes in CF. Pediatr Pulmonol. 2011;46:31-5.

27. Morrow BM, Argent AC, Zar HJ, Westwood AT. Improvements in lung function of a pediatric cystic fibrosis population in a developing country. J Pediatr (Rio J). 2008;84:403-9.

28. Hart N, Tounian P, Clément A, Boulé M, Polkey MI, Lofaso F, et al. Nutritional status is an important predictor of diaphragm strength in young patients with cystic fibrosis. Am J Clin Nutr. 2004;80:1201-6.

29. Martínez-Costa C, Escribano A, Núñez Gómez F, García-Maset L, Luján J, Martínez-Rodríguez L. Nutritional intervention in children and adolescents with cystic fibrosis. Relationship with pulmonary function. Nutr Hosp. 2005;20:182-8.

30. Scagliusi FB, Lancha Júnior AH. Subnotificação da ingestão energética na avaliação do consumo alimentar. Rev Nutr. 2003; $16: 471-81$

\author{
Correspondence: \\ Matias Epifanio \\ Hospital São Lucas da \\ Pontifícia Universidade Católica do Rio Grande do Sul \\ Av. Ipiranga, 6690, 20 andar \\ CEP 90610-000 - Porto Alegre, RS - Brazil \\ Tel.: +55 (51) 9999.6248 \\ E-mail: mepifanio@hotmail.com
}

